\title{
Gaming for Meaningful Interactions in Teleworking Lessons Learned during the COVID-19 Pandemic from Integrating Gaming in Virtual Meetings
}

\author{
FERNANDO KLEIMAN, Faculty of Technology, Policy \& Management, Delft University of Technology \\ SEBASTIAAN MEIJER, Royal Institute of Technology \\ MARIJN JANSSEN, Faculty of Technology, Policy \& Management, Delft University of Technology
}

\begin{abstract}
The recent need for social-distancing caused by COVID-19 resulted in working remotely, which can cause loneliness and disconnect from the organization. The pandemic stimulated people to look for novel ways to interact and, at the same time, socialize with each other. The change to home office increased the number of people using digital video calls; however, these impose restrictions on social bonding. In this commentary, we argue that the social bonding capacity of video calls can be increased by using games. Playing games can create a common object with shared goals, which can give players the feeling of being in the same environment, belonging to the same organization, working on joint objectives, and give an enjoyable experience. All work activities will unlikely return to the office after the pandemic is over, and preparing for remote working and socialization is needed. We recommend several avenues for research, including researching the concepts of online socialization and evaluating the effectiveness of gaming.
\end{abstract}

CCS Concepts: • Applied computing $\rightarrow$ E-government; • Social and professional topics $\rightarrow$ Government technology policy;

Additional Key Words and Phrases: Digital government, public servants, meaningful interaction, collaboration, gaming, video call, teleconferencing, teleworking, COVID-19

ACM Reference format:

Fernando Kleiman, Sebastiaan Meijer, and Marijn Janssen. 2020. Gaming for Meaningful Interactions in Teleworking Lessons Learned during the COVID-19 Pandemic from Integrating Gaming in Virtual Meetings. Digit. Gov.: Res. Pract. 1, 4, Article 31 (September 2020), 5 pages.

https://doi.org/10.1145/3416308

\section{INTRODUCTION}

COVID-19 imposed significant changes in the working routines of many people. The need to transfer face-toface communication to video calls for professionals has resulted in new work and social challenges. Work-wise, it demanded learning to prioritize remote work and finding ways for using digital meetings to coordinate work. Also, social life was affected, as the efforts for staying home result in not being able to meet people face-to-face.

Authors' addresses: F. Kleiman and M. Janssen, Faculty of Technology, Policy \& Management, Delft University of Technology, Jaffalaan, 5, 2628BX Delft, The Netherlands; emails: \{f.kleiman, M.F.W.H.A.Janssen\}@tudelft.nl; S. Meijer, Royal Institute of Technology, Hälsovägen 11 C, Huddinge, Sweden; email: sebas@sebastiaanmeijer.com.

This work is licensed under a Creative Commons Attribution International 4.0 License.

(c) 2020 Copyright held by the owner/author(s).

2639-0175/2020/09-ART31

https://doi.org/10.1145/3416308

Digital Government: Research and Practice, Vol. 1, No. 4, Article 31. Publication date: September 2020. 
Many public servants needed to adopt new routines that risk losing the feeling of belonging to the organization. Efforts to adapt to the new situation generated new experiences and lessons to improve digital calls and to telework in virtual interactive experiences.

Public servants have adapted a variety of tools for remote working. Playing games through video calls were used to share time, acquire new skills, learn, give attention to others, and last but not least, to have fun. Our experiences show that this video-call gaming has been surprisingly successful, with participants declaring their feeling of belonging, sharing laughs and activities in what Huizinga [7] framed as a limited moment of suspension of time and space. By having the game as a common boundary object [14], meaning can be given to social interactions, the sense of presence and belonging to the organization can be increased as well as having meaningful human contact [3]. Our experience of having participants in game sessions in different countries, living in various time zones, and having diverse backgrounds showed the potential for fostering the use of gaming to get people closer and more connected in virtual calls. These personal experiences can be transferable to organizations and governments, as the goal of this commentary is to discuss possible ways of online interactions and to derive a further research agenda. This commentary is structured as follows: first, an overview of the context and limitations found on digital video call communication is presented; different forms of online interaction are discussed next; findings for gaming to video call that can be applied to work and personal life are explored; finally, conclusions are drawn and research suggestions made.

\section{LIMITATIONS TO VIRTUAL MEETINGS}

Personal life and work routines have been changed for many people, and they needed to adapt to the new social distancing conditions. Social distancing resulted in loneliness - the feeling of being isolated from colleagues and friends, resulting in fatigue and even depression. Before COVID-19, depression was already considered one of the major diseases of this century [12], and this risk escalates with social isolation. The situation could be even more sensible depending on the home circumstances of living alone or sharing a dwelling. In such a situation, one of the main strategies to fight loneliness is creating online social gatherings.

There are many differences perceived in this new normal of working from home. Work and meetings are merely reduced to passively watching a screen. There is no walking to the coffee machine with others to grab a beverage or have small talk, as socialization is hidden in the daily routines in the office. Social distancing resulted in fatigue, boredom, and even social disconnection when moving to video calls. Still, better than being alone, the increase in video-conferencing as a way out was massive. Furthermore, with less distraction, the span of attention is also limited, which might result in lower productivity.

The loss of interaction is a significant influence. It is not natural to watch a screen and wait for your turn to talk. Spontaneity is reduced by having to wait for "moment of reaction" to express a thought. For sure, the addition of politeness happens, but not all of it was needed as feelings lag behind.

\section{GAMING AND VIDEO CALLS}

Many organizations embraced video calls without considering other forms, which may have different benefits. Gaming is a highly interactive activity in which all participants are active at the same time, instead of merely watching and waiting for their moment to speak up. Whereas in the early years, players played against the computer, nowadays they play with each other. From regular online one-on-one co-op games to massive multiplayer online games (MMO), many resources have been developed-live broadcast with chat interactions, real-time voice communications.

A videogame has a virtual plot that runs on a screen, and people interact using images. Social interactions occur through virtual avatars and characters. Before COVID-19, 63\% of players already declared to play with others. Many people are used to playing face-to-face games; however, playing serious games is less common $[1,4]$. Some recent gaming initiatives even focus on e-government, cyber-security, and open data [2, 6, 9]; still, there is a lot to be explored in terms of using games for public servants.

Digital Government: Research and Practice, Vol. 1, No. 4, Article 31. Publication date: September 2020. 
Table 1. Benefits of Games in Video Calls

\begin{tabular}{|c|c|c|}
\hline Benefits of gaming & Explanation & Examples \\
\hline $\begin{array}{l}\text { Meaningful interaction with a } \\
\text { common object (game) }\end{array}$ & $\begin{array}{l}\text { In the "magic circle"* of the game, } \\
\text { people interact with common rules and } \\
\text { objects of play }\end{array}$ & Drawing in Gartic.io \\
\hline Increased sense of belonging & $\begin{array}{l}\text { Interacting together enables people to } \\
\text { feel closer to each other }\end{array}$ & $\begin{array}{l}\text { Virtual playrooms with friends } \\
\text { in Houseparty }\end{array}$ \\
\hline Learning new skills & $\begin{array}{l}\text { Increase commitment to learning } \\
\text { processes }\end{array}$ & $\begin{array}{l}\text { Guessing words in Just One or } \\
\text { mimic games }\end{array}$ \\
\hline Share experiences & $\begin{array}{l}\text { The game journey can create joint } \\
\text { narratives and communities }\end{array}$ & $\begin{array}{l}\text { Following up sessions of all } \\
\text { the games }\end{array}$ \\
\hline Fun & $\begin{array}{l}\text { Trigger surprise, challenge, and } \\
\text { happiness }\end{array}$ & $\begin{array}{l}\text { Any players face after game } \\
\text { sessions }\end{array}$ \\
\hline
\end{tabular}

*Based on Klabbers [8] idea of games as a total experience that happens within its imaginary space, the magic circle.

Games are part of human life, embodied in our nature for reasons ranging from social interaction to acquiring specific skills [5, 7]. Different from videogames, digital face-to-face games contain a connecting social environment, including real touch, sounds, and laughs, which create a suitable environment for social bonding.

Some specialized websites released apps to play during the pandemic collectively. For example, the website Playcards and Tabletopia provides a card simulation system. Gartic.io offers a drawing platform for guessing words to be drawn. The Houseparty app was accused of leaking their participants' data. ${ }^{1}$ Misuse of behavior data and online surveillance is an important research topic to be addressed.

We used the quarantine situation to experiment with online face-to-face games, particularly board games, as part of video calls. These games demand the presence of all players at the same time. Their game designs can be adapted to enabling playing through virtual calls. Indeed, asynchronous versions are possible, and more research is needed in this direction.

During five weeks, starting in mid-April, game nights were organized. Fifteen different researchers, public servants, and others joined different sessions, having a maximum of 10 participants in a single session. One of the participants would lead the session and suggest the game to play. It enabled everybody to select a game and different games were tested. Both games based on decentralized apps and centralized dashboards were played.

Games such as Gartic.io and Houseparty do not demand a central screen. These are games played through an app that gives individual feedback for each of the players. We improved the gameplay by connecting a video call, which allowed us to see each other's reactions. On the one hand, these games enabled more people to join and play; on the other hand, less personal contact seemed to reduce social bonding through the gaming experience, even with the video meeting.

If using a board, as with Codenames or Azul, one main screen is shared by a game coordinator and used as a reference for the other participants. Players only see the board in which the coordinator would move the pieces. In this case, the limitation of having one board and one main screen turned out to be more engaging, as the group of players would need to see the same physical artifact.

A third type is the gameplay of fust One. No central screen or app was needed, and a coordinator randomly selected words that needed to be guessed by the players. Besides a standard video call for interaction and gameplay, each event had a dedicated instant-messaging group so people could exchange messages during playing. Also, classic gameplays like hang-man, mimic, and quizzes were integrated into video calls and affected socialization and meaningful interaction. Different languages and difficulties were tested to increase social interaction. The

\footnotetext{
${ }^{1}$ https://techcrunch.com/2020/03/31/houseparty-privacy/.
} 
results showed that the various games yield different benefits, as shown in Table 1. Several authors have provided overviews of typical gaming benefits $[10,11,13]$. In the table, we explain each of the benefits and provide an illustrative example.

The games can be integrated into video calls at the start or during the calls. At the start, it can activate the participants or be an integral part of accomplishing learning objectives. What moment is most effective for socialization requires further research. The board games were not originally designed for being integrated into video-conferencing and demanded adaption. There is room for improving gameplay, and the number of games designed specifically for video calls is rising, as listed in the Appendix. Nevertheless, games might also have negative impacts, and research is needed to avoid the dark side. Connecting the chosen game with the purpose of its use in a meeting is another further research direction.

\section{CONCLUSIONS AND FURTHER RESEARCH AGENDA}

Social distancing and its impacts on meaningful interaction are hardly researched. Integrating gaming into video calls can tackle the social problems of being lonely and, at the same time, create a sense of belonging to the organization. Even productivity can be boosted by fighting boredom, fatigue, and tiredness.

Our experiences show that the use of gaming in video calls results in more meaningful experiences for players. The existence of a common object created a greater sense of belonging for the participants, even if the connection failed. Different games engage participants differently, suggesting that there might be elements in games that are more or less appropriate for socialization and the gaining of different benefits.

Gaming through video calls is still unexplored. Its use can also be extended to other experiences, such as on-the-job training and learning. Possible research questions include the following:

- How to combine gaming in video calls?

- At what stage in a video call should gaming be used?

- What level of socialization is needed?

- How to ensure a healthy mix of various interactive forms?

- Which types of games are suitable for meaningful socialization, learning, and working?

- How to use online games for learning and developing new skills?

- How do meaningful interactions and gaming influence working effectivity?

- What is the impact of meaningful interactions and gaming on isolation, fatigue, and depression?

- Which infrastructure is suitable for secure playing to avoid surveillance and observing behavior?

The increased social bonding and sense of belonging experienced by some of the participants in our experiments show the opportunities. After the COVID-19 pandemic, working remotely will likely be here to stay, and gaming through video calls can play an essential role by providing meaningful interaction.

\section{APPENDIX - LIST OF GAME REFERENCES}

Azul - https://www.nextmovegames.com/en/home/48-azul.html

Black Stories - https://www.black-stories.de/

Codenames - https://codenamesgame.com/

Exploding kittens - https://explodingkittens.com/

Gartic.io - https://gartic.com/

Houseparty - https://houseparty.com/

Just One - https://justone-the-game.com/index.php?lang=en

Playcards - http://playingcards.io/

Tabletopia - https://tabletopia.com/

Digital Government: Research and Practice, Vol. 1, No. 4, Article 31. Publication date: September 2020. 


\section{ACKNOWLEDGMENTS}

The authors would like to thank the many participants that joined the video call games during the quarantined social distancing to flatten the curve of COVID-19 in their countries.

\section{REFERENCES}

[1] C. C. ABT. 1987. Serious Games. University Press of America.

[2] A. M. Ahmed, Q. H. Mehdi, R. Moreton, and A. Elmaghraby. 2014. Towards the use of serious games for effective e-government service. In Proceedings of the Computer Games: AI, Animation, Mobile, Multimedia, Educational and Serious Games Conference (CGAMES'14) IEEE, $1-6$.

[3] G. B. D. f. Communities, L. Government, and N. C. Forum. 2009. Guidance on Meaningful Interaction: How Encouraging Positive Relationships Between People Can Build Community Cohesion. Communities and Local Government Publications.

[4] D. Djaouti, J. Alvarez, J. P. Jessel, and O. Rampnoux. 2011. Origins of serious games. In Serious Games and Edutainment Applications Springer, 25-43.

[5] L. Hassan. 2016. Governments should play games. Simul. Gam. 48, 2 (2016), 249-267. DOI : http://dx.doi.org/10.1177/1046878116683581

[6] M. Hendrix, A. AL-Sherbaz, and V. Bloom. 2016. Game based cyber security training: are serious games suitable for cyber security training? Int. f. Ser. Games 3, 1 (2016). DOI : http://dx.doi.org/10.17083/ijsg.v3i1.107

[7] J. Huizinga. 1949. Homo Ludens. Routledge.

[8] J. H. Klabbers. 2009. The Magic Circle: Principles of Gaming \& Simulation. Brill Sense.

[9] F. Kleiman and M. Janssen. 2018. Gaming to improve public policies by engaging local governments in open data policy-making. In Proceedings of the 19th Annual International Conference on Digital Government Research: Governance in the Data Age. ACM, 99.

[10] R. N. Landers, E. M. Auer, A. B. Collmus, and M. B. Armstrong. 2018. Gamification science, its history and future: Definitions and a research agenda. Simul. Gam. 49, 3 (2018), 315-337. DOI : http://dx.doi.org/10.1177/1046878118774385

[11] J. Mcgonigal. 2011. Reality Is Broken: Why Games Make Us Better and How They Can Change the World. Penguin.

[12] World Health Organization. 2012. Depression: A global crisis. World mental health day, October 10, 2012. In Proceedings of the World Federation for Mental Health Conference.

[13] K. Salen and E. Zimmerman. 2005. Game design and meaningful play. Handbook Comput. Game Stud. 59, 79 (2005).

[14] S. L. Star and J. R. Griesemer. 1989. Institutional ecology, translations and boundary objects: Amateurs and professionals in Berkeley's Museum of Vertebrate Zoology, 1907-39. Soc. Stud. Sci. 19, 3 (1989), 387-420.

Received June 2020; revised July 2020; accepted August 2020

Digital Government: Research and Practice, Vol. 1, No. 4, Article 31. Publication date: September 2020. 